\title{
PENGARUH METODE CHARGING MATERIAL TERHADAP ELECTRICAL POWER PADA PROSES PELEBURAN ELECTRIC ARC FURNACE DI SMS-1 DAN SMS-2 PT. GUNUNG RAJA PAKSI CIKARANG BARAT BEKASI
}

\author{
Muhammad Jhony Andre ${ }^{1}$, Sudaryanto ${ }^{2}$ \\ 1,2Prodi Teknik Metalurgi, Jurusan Teknik Pertambangan, Fakultas Teknologi Mineral, \\ UPN "Veteran" Yogyakarta, Jl. Babarsari 2, Tambakbayan, Depok, Sleman, Yogyakarta, 55281 \\ E-mail: mjhonyandrews@gmail.com ${ }^{1}$, sdaryanto20@gmail.com $^{2}$ \\ $(+62$ 857-9556-3139, +62 878-3950-1319)
}

\begin{abstract}
Steel is a metal alloy with iron as the basic element and carbon as the main alloying element. The carbon content in steel ranges from $0.2 \%$ to $2.1 \%$ by weight according to the grade. The addition of carbon content to steel can increase its hardness and tensile strength, but on the other hand it makes it brittle and reduces its ductility. Steelmaking is the process of producing steel from iron ore and/or scrap. In steelmaking, impurities such as nitrogen, silicon, phosphorus, sulfur and excess carbon (the most important impurities) are removed from the iron source, and alloying elements such as manganese, nickel, chromium, carbon, and vanadium are added to produce different grades of steel. Electric Arc Furnace (EAF) is one of the common and popular technologies used in the steel industry. EAF is used to produce carbon steel and alloy steel mainly by recycling iron scrap. In EAF, the manufactured scrap and/or unit iron - such as DRI, pig iron, iron carbide is smelted and converted into high quality steel using a high power electric arc without changing the electrochemical properties of the metal. Scrap loading can be done by 2 methods, namely a scrap loading system with a bucket (conventional charging) and a continuous scrap loading system (continuous scrap charging). This scrap loading method affects the course of the smelting process starting from the electrical power and the length of time the smelting process takes.
\end{abstract}

Keyword: Steel; Electric Arc Furnace; Scrap Charging; Electrical Power

\begin{abstract}
Abstrak
Baja adalah logam paduan dengan besi sebagai unsur dasar dan karbon sebagai unsur paduan utamanya. Kandungan karbon dalam baja berkisar antara $0.2 \%$ hingga $2.1 \%$ berat sesuai gradenya. Penambahan kandungan karbon pada baja dapat meningkatkan kekerasan (hardness) dan kekuatan tariknya (tensile strength), namun di sisi lain membuatnya menjadi getas (brittle) serta menurunkan keuletannya (ductility). Steelmaking adalah proses produksi baja dari bijih besi dan/atau scrap . Dalam pembuatan baja, pengotor seperti nitrogen, silikon, fosfor, belerang dan kelebihan karbon (pengotor yang paling penting) dihilangkan dari sumber besi, dan elemen paduan seperti mangan, nikel, kromium, karbon, dan vanadium ditambahkan untuk menghasilkan nilai yang berbeda dari baja. Electric Arc Furnace (EAF) adalah salah satu teknologi yang umum dan popular digunakan dalam industri baja. EAF digunakan untuk memproduksi baja karbon dan baja paduan terutama dengan mendaur ulang scrap besi. Dalam EAF, scrap dan / atau unit besi yang diproduksi - seperti DRI, pig iron, besi karbida dilebur dan diubah menjadi baja berkualitas tinggi menggunakan busur listrik daya tinggi tanpa mengubah sifat elektrokimia logam. Pemuatan scrap (scrap charging) dapat dilakukan dengan 2 metode yaitu sistem pemuatan scrap dengan
\end{abstract}


bucket (conventional charging) dan sistem pemuatan scrap secara kontinyu (continuous scrap charging). Metode pemuatan scrap ini berpengaruh pada jalannya proses peleburan mulai dari electrical power maupun lama waktu proses peleburannya.

Kata kunci: Baja; Electric Arc Furnace; Pemuatan Scrap; Tenaga Listrik

\section{Pendahuluan}

Baja adalah logam paduan dengan besi sebagai unsur dasar dan karbon sebagai unsur paduan utamanya. Kandungan karbon dalam baja berkisar antara $0.2 \%$ hingga $2.1 \%$ berat sesuai grade-nya. Fungsi karbon dalam baja adalah sebagai unsur pengeras. Unsur paduan lain yang biasa ditambahkan selain karbon adalah mangan (manganese), krom (chromium), vanadium, dan nikel. Dengan memvariasikan kandungan karbon dan unsur paduan lainnya, berbagai jenis kualitas baja bisa didapatkan. Penambahan kandungan karbon pada baja dapat meningkatkan kekerasan (hardness) dan kekuatan tariknya (tensile strength), namun di sisi lain membuatnya menjadi getas (brittle) serta menurunkan keuletannya (ductility).

Steelmaking adalah proses produksi baja dari bijih besi dan/atau scrap. Dalam pembuatan baja, pengotor seperti nitrogen, silikon, fosfor, belerang dan kelebihan karbon (pengotor yang paling penting) dihilangkan dari sumber besi, dan elemen paduan seperti mangan, nikel, kromium, karbon, dan vanadium ditambahkan untuk menghasilkan nilai yang berbeda dari baja .

Electric arc furnace merupakan salah satu teknologi yang umum dan popular digunakan dalam industri baja. Sekitar seperempat baja dunia diproduksi dengan metode EAF, yang menggunakan busur listrik intensitas tinggi untuk melelehkan scrap baja dan mengubahnya menjadi baja cair dengan komposisi kimia dan suhu tertentu. Electric arc furnace (EAF) diciptakan pada tahun 1889 oleh Paul Héroult, pada awalnya digunakan terutama untuk produksi baja khusus, tetapi kemudian dipatenkan sebagai salah satu proses pembuatan baja utama di abad 20. Pada tahun 2018, proses EAF memasok 523.918.000 ton baja di seluruh dunia, atau $28,9 \%$ dari total produksi baja kasar.

Bahan baku dalam pembuatan baja di EAF adalah scrap baja, dan ketersediaannya yang murah dan berkualitas sangat penting. Kualitas scrap menjadi semakin penting ketika pembuatan baja daktilitas tinggi, yang harus memiliki kandungan residu total maksimum (yaitu tembaga, kromium, nikel, molibdenum dan timah) sebesar $0,2 \%$. Sebagian besar residu ini ada dalam scrap, dan bukannya teroksidasi selama pembuatan baja, mereka malah menumpuk dan meningkat dalam recycled scrap. Dalam kasus seperti itu, beberapa steel melting shop meningkatkan beban scrap mereka dengan direct-reduced iron atau cold blast-furnace iron, yang tidak mengandung residu. Umumnya, kandungan karbon, nitrogen dan residu 
yang lebih tinggi membuat proses EAF kurang menarik untuk produksi baja karbon rendah yang ulet.

Selain scrap, material lain yang bisa digunakan sebagai bahan baku dalam proses peleburan di EAF ini antara lain DRI, pig iron, Hot Briquet Iron (HBI), dan hot metal. Bahan baku dapat berupa scrap hingga $100 \%$ atau berbagai campuran hot metal, pig iron, DRI (panas dan/atau dingin) dan HBI. Di seluruh dunia, scrap mencakup sekitar $75 \%$ bahan baku EAF, sementara DRI dan HBI mencakup sekitar $15 \%$ dan sisanya (10\%) ditutupi oleh pig iron dan hot metal.

Dalam proses peleburan EAF terdapat proses yang pemuatan material/ charging material. Pemuatan scrap dapat dilakukan dengan 2 metode yaitu sistem pemuatan scrap dengan bucket (conventional charging) dan sistem pemuatan scrap secara kontinyu (continuous scrap charging).

Dalam teknologi konvensional, scrap dimuat dengan bucket dari atas dan ditempatkan di tungku freeboard di mana sebagian besar dilebur oleh busur listrik /elektroda dengan sedikit intervensi dari burner dan sumber energi lainnya

Sedangkan dalam Continuous Scrap Charging, material diumpankan secara kontinyu ke dalam tungku EAF. Continuous Scrap Charging terbagi menjadi beberapa jenis antara lain Continuous Scrap Charging with Consteel EAF, Shaft Furnaces with Fingers Retaining Scrap, Shaft Furnaces with Pushers of the COSS-Type.
PT. Gunung Raja Paksi Tbk merupakan salah satu perusahaan peleburan baja yang terletak di Cikarang Barat, Bekasi, Jawa Barat. Di PT GRP, proses pembuatan semi finished product nya dilakukan di Steel Melting Shop 1 (SMS1) dan Steel Melting Shop 2 (SMS 2). Proses yang terjadi di SMS-1 dan dan SMS-2 yaitu proses peleburan dengan electric arc furnace, proses pemurnian dengan ladle furnace, dan proses pengecoran dengan continuous casting machine. Pada proses peleburan di EAF SMS-1 dan SMS-2 memiliki metode pemuatan material (charging material) yang berbeda. Di SMS-1 menggunakan sistem pemuatan konvensional yang dikombinasikan dengan sistem COSS shaft furnace dengan bantuan pusher. Sedangkan di SMS-2 hanya menggunakan sistem konvensional saja.

Perbedaan penggunaan metode charging material tersebut dapat mempengaruhi kinerja selama peleburan seperti pada electrical power dan juga waktu peleburannya. Oleh karena itu penulis ingin membahas mengenai perbedaan metode charging material di SMS-1 dan SMS-2 serta mempelajari pengaruh dari metode charging material tersebut terhadap electrical power selama proses peleburan di EAF.

\section{Material Dan Metode Penelitian}

\section{Material}

Material yang digunakan pada proses peleburan baja ini antara lain :

1. Scrap

2. Kapur (lime)

3. Karbon 
4. Oksigen

5. $\mathrm{MgO}$

6. Gas Argon

\section{Metode}

Penelitian ini dimulai dari pengamatan berupa proses produksi di EAF SMS-1 dan SMS-2, mencari tahu kekurangan dan kelebihan dari proses produksi dan mengumpulkan data yang diperlukan. lalu dilanjutkan pengolahan data aktual untuk dapat mengetahui pengaruh dari metode charging material terhadap electrical power pada proses peleburan EAF di SMS-1 dan SMS-2. Setelah itu, data tersebut dianalisis seberapa besar pengaruh metode charging tersebut terhadap electrical power.

Adapun flowchart yang digunakan dalam kerja praktek ini adalah sebagai berikut.

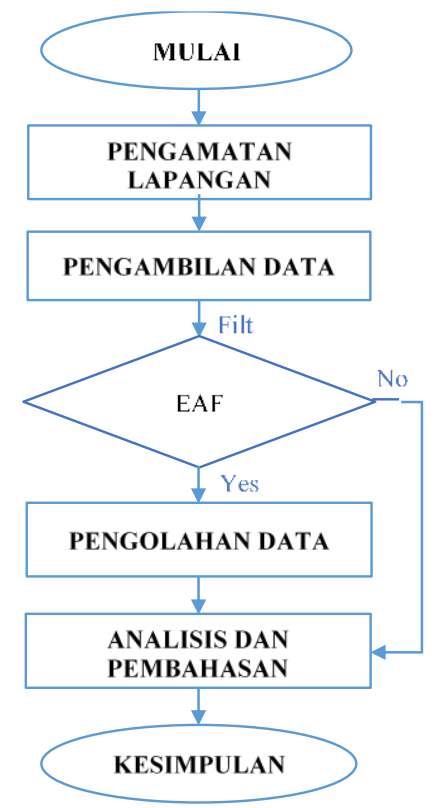

Gambar 1. Flowchart Kerja Praktek

\section{Proses Peleburan EAF di SMS-1}

Di departemen SMS-1, produk yang dibuat antara lain beam blank, blooms, dan juga billet. Untuk grade dari bajanya tidak terlalu banyak sehingga proses peleburan lebih mudah dilakukan dibandingkan dengan di SMS-2. Kapasitas tungku EAF di SMS-1 dapat menampung sekitar \pm 125 ton scrap.

\section{Proses Charging Material}

Proses peleburan di SMS-1 dimulai dengan pemberian $\mathrm{CaO} /$ lime sebanyak $\pm 2000 \mathrm{~kg}$, lime disini berfungsi sebagai flux/ bahan tambah untuk mengikat slag. Untuk metode charging material di SMS-1 menggunakan metode konvensional dan dilanjutkan dengan shaft furnace dengan pendorong tipe COSS (Continuous Optimized Shaft System). Pada proses peleburannya diawali dengan charging menggunakan bucket scrap kemudiaan dilanjutkan dengan shaft furnace.

Setelah dimasukkan lime, maka dilanjutkan dengan memasukkan 1 bucket scrap ke dalam tungku EAF. Setelah itu roof bergerak menutup tungku dan elektroda turun, lalu proses peleburan dimulai.

\section{Proses Peleburan}

Pada awal peleburan, aliran listrik pada elektroda (tap) diatur pada aliran yang paling rendah dan dinaikkan secara bertahap sembari menunggu scrap melting.

Selama proses peleburan berlangsung, dilakukan penambahan scrap secara 
berkala. Untuk penambahan scrap dilakukan melalui shaft furnace dan didorong oleh pusher tipe COSS. Selama proses peleburan dilakukan pemuatan ke dalam shaft furnace, pemuatan dilakukan menggunakan bucket kotak ukuran kecil. Dalam satu kali proses peleburan biasanya dilakukan charging ke dalam shaft furnace sebanyak 2-4 bucket ukuran kecil, tergantung dari kualitas scrap nya. Di dalam shaft furnace, scrap mengalami pereheating dari off gas yang keluar dari tungku EAF selama proses peleburan berlangsung. Ketika scrap sudah mencapai bagian bawah shaft furnace maka akan didorong menggunakan pusher COSS dan jatuh ke tungku EAF. Scrap yang masuk ke dalam tungku EAF sudah mengalami preheating sehingga mempercepat proses peleburan di EAF.

Selama proses peleburan juga dilakukan penambahan oksigen, lime, dan $\mathrm{MgO}$. Oksigen diinjeksikan melalui burner. Burner membantu elektroda selama proses peleburan. Pada burner ini terdapat oksigen, gas, dan angin yang diinjeksikan dalam bentuk api. Selain itu, tingkatan dari burner juga perlu diatur dan dinaikkan secara bertahap. Untuk tingkatan dari burner itu sendiri yaitu flushing, pilot, low, medium, high, dan lance. Untuk proses peleburan bucket scrap yang pertama dan kedua, tingkatan maksimal dari burner nya adalah medium. Untuk tingkatan high dan lance digunakan ketika scrap sudah melting.

Penambahan lime dilakukan selama proses peleburan berlangsung dan dilakukan secara berkala melalui conveyor. Untuk penambahan lime ini sebanyak $\pm 3000 \mathrm{~kg}$. Selain itu juga dilakukan penambahan $\mathrm{MgO}$. Untuk $\mathrm{MgO}$ yang ditambahkan yaitu sebanyak $\pm 1000 \mathrm{~kg}$.

\section{Proses Pemurnian (Refining)}

Setelah scrap mencair secara keseluruhan maka proses pemurnian (refining) dimulai. Ketika proses refining, tingkatan burner dapat dinaikkan hingga ke level high dan lance. Pada proses refining dilakukan injeksi karbon secara berkala.

Selama proses refining berlangsung, dilakukan pengambilan sampel dan juga pengecekan temperatur. kadar karbon yang diinginkan yaitu berkisar antara 0,1\%-0,14\%. Pengecekan kadar karbon dapat dilakukan dengan 2 cara, yaitu cara manual dan laboratorium (QC). Jika kadar karbon terlalu rendah maka diperlukan injeksi karbon lagi secara terus menerus untuk mencapai kadar karbon yang diinginkan. Injeksi karbon dilakukan pada temperatur 1560$1590^{\circ} \mathrm{C}$. Akan tetapi jika kadar karbon terlalu tinggi maka perlu dikurangi dengan melakukan injeksi oksigen sampai kadar karbon sesuai dengan komposisi yang diinginkan.

\section{Proses Penuangan (Tapping)}

Setelah kadar karbon yang diinginkan sudah tercapai dan suhu untuk tapping sudah memenuhi $\left(\mathrm{Tmin}=1600^{\circ} \mathrm{C}\right)$, maka proses tapping bisa dilakukan. Pada proses tapping ini dilakukan penambahan lime, SiMn, dan juga FeSi. Penambahan ini dilakukan untuk 
mempermudah jalannya proses di Ladle Furnace (LF) nantinya.

Selama proses tapping diinjeksikan gas argon. Gas argon disini digunakan untuk mixing antara cairan, lime, SiMn, dan FeSi. Setelah proses tapping selesai maka carian di ladle akan dibawa menggunakan ladle car menuju Ladle Furnace untuk dilakukan proses homogenization (chemical control).

\section{Proses Peleburan EAF di SMS-2}

Di departemen SMS-2, produk yang dibuat adalah slab sehingga prosesnya lebih teliti dan grade bajanya juga lebih bervariasi. Komposisi yang dibuat selama proses peleburan tergantung dari permintaan. Secara proses, peleburan di SMS-1 dan SMS-2 hampir sama, yang membedakan hanyalah kapasitas produksi, grade cairan bajanya, serta proses charging materialnya. Pada SMS2, kapasitas dari tungku EAF dapat menampung scrap sebanyak \pm 150 ton dan charging materialnya menggunakan round bucket. Biasanya dalam satu kali heat memerlukan 2-3 round bucket.

\section{Proses Charging Material}

Sebelum melakukan proses peleburan, dilakukan pengecekan sisa cairan setelah tapping pada proses peleburan (heat) sebelumnya, apakah masih ada sisa cairan atau tidak. Proses charging material di SMS-2 menggunakan metode konvensional, dimana pemuatan dilakukan menggunakan bucket dan scrap dijatuhkan melalui bagian bawah bucket ke dalam tungku EAF. Pemasukkan bucket scrap dilakukan secara berkala selama proses peleburan.
Setelah dilakukan pengecekan tadi maka dilanjutkan dengan memasukkan bucket pertama ke dalam tungku EAF. Setelah itu roof bergerak menutup tungku dan elektroda turun, lalu proses peleburan dimulai.

\section{Proses Peleburan}

Pada awal peleburan, aliran listrik pada elektroda (tap) diatur pada aliran yang paling rendah dan dinaikkan secara bertahap sembari menunggu scrap melting. Selama proses peleburan berlangsung, diinjeksikan oksigen melalui burner. Burner membantu elektroda selama proses peleburan. Pada burner ini terdapat oksigen, gas, dan angin yang diinjeksikan dalam bentuk api. Selain itu, tingkatan dari burner juga perlu diatur dan dinaikkan secara bertahap. Untuk tingkatan dari burner itu sendiri yaitu flushing, pilot, low, medium, high, dan lance.

Selama proses peleburan bucket pertama ini juga dilakukan penambahan $\mathrm{CaO} /$ lime dan $\mathrm{MgO}$. Untuk lime yang ditambahkan yaitu sebanyak $\pm 3500 \mathrm{~kg}$, sedangkan untuk $\mathrm{MgO}$ yang ditambahkan yaitu sebanyak $\pm 800 \mathrm{~kg}$. Penambahan ini dilakukan secara bertahap hingga tercapai sebanyak $\pm 3500 \mathrm{~kg}$ untuk lime dan $\pm 800 \mathrm{~kg}$ untuk $\mathrm{MgO}$.

Setelah dilakukan injeksi oksigen, lime, dan $\mathrm{MgO}$ maka tinggal menunggu scrap dari bucket pertama melting. Setelah scrap melting maka boleh ditambahkan untuk scrap bucket kedua. Tungku berhenti melebur, elektroda diangkat dan roof bergeser, kemudian scrap bucket 
kedua dimasukkan. Lalu roof ditutup dan elektroda diturunkan untuk melanjutkan proses peleburan.

Pada peleburan bucket kedua ini, aliran listik pada elektroda perlu diatur seperti pada peleburan bucket yang pertama tadi dimana aliran listrik pada elektroda dimulai dari yang paling rendah kemudian dinaikkan secara berkala. Untuk injeksi oksigen lewat burner juga diatur tingkatan burner nya seperti pada peleburan bucket pertama, mulai dari yang paling rendah hingga tingkat medium dan dinaikkan secara berkala.

Selama proses peleburan bucket kedua juga dilakukan penambahan lime dan $\mathrm{MgO}$. Untuk lime yang ditambahkan yaitu sebanyak $\pm 1500 \mathrm{~kg}$, sedangkan untuk $\mathrm{MgO}$ nya ditambahkan sebanyak $\pm 400 \mathrm{~kg}$. Penambahan ini dilakukan secara bertahap hingga tercapai sebanyak $\pm 1500 \mathrm{~kg}$ untuk lime dan \pm 400 $\mathrm{kg}$ untuk $\mathrm{MgO}$. Setelah itu menunggu hingga scrap mencair. Setelah scrap mencair maka boleh ditambahkan untuk scrap bucket ketiga. Tungku berhenti melebur, elektroda diangkat dan roof bergeser, kemudian scrap bucket ketiga dimasukkan. Lalu roof ditutup dan elektroda diturunkan untuk melanjutkan proses peleburan.

Pada proses peleburan bucket ketiga ini sudah tidak dilakukan penambahan lime dan $\mathrm{MgO}$. Pada proses peleburan bucket ketiga ini tinggal dilakukan injeksi oksigen dan carbon.

\section{Proses Pemurnian (Refining)}

Setelah scrap mencair secara keseluruhan maka proses pemurnian (refining) dimulai. Ketika proses refining, tingkatan burner dapat dinaikkan hingga ke level high dan lance. Pada proses refining dilakukan injeksi karbon. Untuk awal injeksi karbon, diinjeksikan sebanyak $\pm 200 \mathrm{~kg}$ karbon secara berkala. Selama proses refining berlangsung, dilakukan pengambilan sampel dan juga pengecekan temperatur. Pengambilan sampel tadi dilakukan untuk dikirimkan ke quality control (QC) untuk dilakukan pengecekan komposisi dari cairan, apakah sudah sesuai dengan grade yang diinginkan atau belum.

Apabila komposisi sudah sesuai maka dilakukan pengecekan temperatur, jika temperatur masih dibawah $1600^{\circ} \mathrm{C}$ maka proses peleburan dilanjutkan hingga temperatur di atas $1600^{\circ} \mathrm{C}$. Apabila temperatur sudah di atas $1600^{\circ} \mathrm{C}$ maka dilakukan proses tapping/ penuangan cairan ke ladle.

\section{Proses Penuangan (Tapping)}

Sebelum dilakukan tapping slag perlu dibuang terlebih dahulu melalui slag door, setelah slag dibuang baru dilakukan proses tapping. Setelah itu proses tapping dilakukan. Pada proses tapping ini dilakukan penambahan lime, $\mathrm{SiMn}, \mathrm{FeSi}$, dan juga $\mathrm{Al}$ ingot. Penambahan lime, SiMn, FeSi, dan juga Al ingot ini digunakan untuk homogenization (control chemistry) di ladle furnace nantinya. Al ingot digunakan untuk proses alumunium kill steel. Untuk alumunium ingot yang ditambahkan yaitu sebanyak $220 \mathrm{~kg}$. Untuk jumlah penambahan lime, SiMn, 
dan FeSi mengikuti permintaan dari operator LF.

Selama proses tapping diinjeksikan gas argon. Gas argon disini digunakan untuk mixing antara cairan, lime, SiMn, dan FeSi. Setelah proses tapping selesai maka carian di ladle akan dibawa menggunakan ladle car menuju Ladle Furnace untuk dilakukan proses homogenization (chemical control).

\section{Metode Charging Material SMS-1 dan SMS-2}

Metode charging material pada SMS-1 dan SMS-2 memiliki perbedaan. Pada SMS-1, pemuatan materialnya menggunakan shaft furnace dengan bantuan pendorong (pusher) tipe COSS dan dikombinasikan dengan sistem konvensional. Sedangkan pada SMS-2, pemuatan materialnya menggunakan sistem konvensional (conventional furnace) saja.

1. COSS Shaft Furnace System di SMS-1

Untuk sistem charging material di SMS1 tidak hanya menggunakan sistem shaft furnace dengan pusher tipe COSS, melainkan juga menggunakan sistem konvensional yaitu dengan menggunakan satu round bucket scrap pada awal proses peleburan. Setelah itu proses pemuatan baru dilakukan melalui shaft furnace. Dalam teknologi ini, shaft furnace digunakan untuk menampung scrap yang akan masuk ke dalam EAF. Di dalam shaft furnace, scrap akan mengalami preheating sebelum dilebur dengan EAF. Proses pemuatan ke dalam tungku EAF nya dibantu dengan pusher tipe COSS. Pusher ini mendorong scrap yang telah mengalami preheating tadi ke dalam tungku EAF. Karena scrap telah mengalami preheating di shaft furnace, maka mempercepat proses peleburan di EAF.

2. Conventional Furnace System di SMS-2

Untuk sistem charging material di SMS2 semuanya menggunakan sistem konvensional. Pemilihan penggunaan sistem ini karena di SMS-2 didesain untuk proses pembuatan slab, yang mana scrap yang dibutuhkan tidak sebanyak di SMS-1, karena sebagian bahan baku berasal dari HBI dan iron ingot.

Dalam teknologi konvensional, scrap charging dilakukan beberapa kali dalam satu kali peleburan dengan round bucket. Biasanya scrap yang masuk berkisar antara 2-3 bucket scrap tergantung dari kualitas scrap nya. Scrap dimuat dengan bucket dan kemudian dibawa ke atas tungku EAF kemudian bagian bawah bucket akan terbuka dan scrap akan jatuh ke dalam tungku EAF. Pada metode ini, scrap tidak mengalami preheating, sehingga sebagian besar scrap nya dilebur oleh busur listrik dengan bantuan dari burner dan sumber energi lainnya. Karena tidak adanya proses preheating menyebabkan proses peleburan di EAF nya berlangsung lebih lama dan power yang dikeluarkan juga lebih banyak.

\section{Hasil Penelitian dan Pembahasan}

Tabel 1 dan 2 merupakan data proses peleburan Electric Arc Furnace di SMS1 dan SMS-2. 
Journal Of Metallurgical Engineering And Processing Technology, Vol. 2, No. 2,

February 2022, pp. 47-58

P-ISSN: 2723-6854, E-ISSN: 2798-1037

Tabel 1. Data Proses EAF SMS-1

\begin{tabular}{|c|c|c|c|c|c|c|c|c|c|c|c|c|c|}
\hline \multirow[b]{2}{*}{ Heat } & \multirow[b]{2}{*}{$\mathrm{EAF}$} & \multirow{2}{*}{$\begin{array}{c}\text { Tap to } \\
\text { Tap } \\
\text { Time }\end{array}$} & \multirow{2}{*}{$\begin{array}{c}\text { Power } \\
\text { on Time } \\
\text { (min) }\end{array}$} & \multirow{2}{*}{$\begin{array}{c}\text { Energy } \\
\text { Consumption } \\
\text { (Mwh) }\end{array}$} & \multirow{2}{*}{$\begin{array}{c}\text { Specific } \\
\text { Energy } \\
\text { (Kwh'ton) }\end{array}$} & \multirow{2}{*}{$\begin{array}{c}\text { Tonnage } \\
\text { (ton) }\end{array}$} & \multicolumn{5}{|c|}{ TOTAL KONSUMSI } & \multirow{2}{*}{$\begin{array}{l}\text { Total } \\
\text { Push } \\
\text { (Cycle) }\end{array}$} & \multirow{2}{*}{$\begin{array}{l}\text { Total } \\
\text { Round } \\
\text { Bucket }\end{array}$} \\
\hline & & & & & & & $\begin{array}{c}\mathrm{O} 2 \\
(\mathrm{Nm} 3)\end{array}$ & $\begin{array}{c}\mathrm{CH} 4 \\
(\mathrm{Nm} 3)\end{array}$ & $\begin{array}{c}\text { Inject } \\
\text { Carbon } \\
(\mathrm{kg})\end{array}$ & $\begin{array}{l}\mathrm{CaO} \\
(\mathrm{kg})\end{array}$ & $\begin{array}{c}\mathrm{MgO} \\
(\mathrm{kg})\end{array}$ & & \\
\hline 03082101 & 1 & 65 & 57 & 45,1 & 434,97 & 103,684 & 2487 & 154 & 810 & 5000 & 1200 & 6 & 1 \\
\hline 03082102 & 1 & 65 & 60 & 44,4 & 425,21 & 104,419 & 2640 & 182 & 2144 & 5000 & 1200 & 4 & 1 \\
\hline 03082103 & 1 & 65 & 55 & 44,2 & 423,3 & 104,419 & 2365 & 138 & 1762 & 5000 & 1200 & 6 & 1 \\
\hline 03082104 & 1 & 64 & 51 & 42,4 & 406,06 & 104,419 & 2344 & 143 & 1908 & 5000 & 1200 & 6 & 1 \\
\hline 03082105 & 1 & 65 & 62 & 49 & 469,26 & 104,419 & 2858 & 183 & 1223 & 5000 & 1200 & 4 & 2 \\
\hline 03082106 & 1 & 65 & 58 & 47,8 & 425,04 & 112,459 & 2316 & 195 & 988 & 4900 & 1200 & 7 & 1 \\
\hline 03082107 & 1 & 65 & 58 & 48,3 & 441,16 & 109,485 & & & 1019 & 4910 & 1200 & 7 & 1 \\
\hline 03082108 & 1 & 65 & 55 & 45,8 & 418,32 & 109,485 & 2305 & 191 & 1041 & 4500 & 1200 & 7 & 1 \\
\hline 03082109 & 1 & 65 & 56 & 45,2 & 432,87 & 104,419 & 2028 & 145 & 1350 & 4931 & 1200 & 6 & 2 \\
\hline 03082110 & 1 & 65 & 56 & 45,3 & 411 & 110,220 & 2249 & 199 & 878 & 6409 & 1200 & 8 & 1 \\
\hline 03082111 & 1 & 65 & 50 & 41,9 & 401,27 & 104,419 & 2185 & 159 & 676 & 4938 & 1200 & 7 & 1 \\
\hline 03082112 & 1 & 65 & 55 & 45,8 & 438,62 & 104,419 & 2479 & 132 & 680 & 4965 & 1200 & 8 & 1 \\
\hline 03082113 & 1 & 65 & 55 & 45,8 & 352,68 & 129,862 & 2079 & 166 & 966 & 3958 & 1200 & 9 & 1 \\
\hline 03082114 & 1 & 65 & 52 & 44,7 & 431,12 & 103,684 & 2089 & 129 & 951 & 4955 & 1200 & 5 & 1 \\
\hline 03082115 & 1 & 64 & 52 & 44,3 & 417,74 & 106,048 & 2529 & 180 & 330 & 4973 & 1200 & 8 & 1 \\
\hline 03082116 & 1 & 65 & 54 & 43 & 417 & 103,117 & 2427 & 180 & 1177 & 4925 & 1200 & 7 & 1 \\
\hline To & & 1038 & 886 & 723 & 6745,62 & 1718,975 & 35380 & 2476 & 17903 & 79364 & 19200 & 105 & 18 \\
\hline
\end{tabular}

Sumber : EAF SMS-1 PT GRP (2021)

Tabel 2. Data Proses EAF SMS-2

\begin{tabular}{|c|c|c|c|c|c|c|c|c|c|c|c|}
\hline \multirow[t]{2}{*}{ Heat } & \multirow{2}{*}{$\begin{array}{l}\text { Tap to Tap } \\
\text { Time } \\
\text { (min) }\end{array}$} & \multirow{2}{*}{$\begin{array}{l}\text { Power on } \\
\text { Time } \\
\text { (min) }\end{array}$} & \multirow{2}{*}{$\begin{array}{c}\text { Energy } \\
\text { Consumption } \\
(\mathrm{Mwh})\end{array}$} & \multirow{2}{*}{$\begin{array}{c}\text { Specific } \\
\text { Energy } \\
\text { (Kwh/ton) }\end{array}$} & \multirow{2}{*}{$\begin{array}{c}\text { Scrap Basket } \\
\text { Weight } \\
\text { (ton) }\end{array}$} & \multirow{2}{*}{$\begin{array}{l}\text { Tonnage } \\
\text { (ton) }\end{array}$} & \multicolumn{5}{|c|}{ TOTAL KONSUMSI } \\
\hline & & & & & & & $\begin{array}{c}\mathrm{O} 2 \\
(\mathrm{Nm} 3)\end{array}$ & $\begin{array}{c}\text { Gas } \\
\text { (Nm3) }\end{array}$ & $\begin{array}{c}\text { Inject } \\
\text { Carbon } \\
(\mathrm{kg})\end{array}$ & $\begin{array}{l}\mathrm{CaO} \\
(\mathrm{kg})\end{array}$ & $\begin{array}{l}\mathrm{MgO} \\
(\mathrm{kg})\end{array}$ \\
\hline 1027082102 & 74,3 & 46,2 & 55,3 & 409 & 135 & 125 & 1975 & 535 & 574 & 5529 & 209 \\
\hline 1027082103 & 65,3 & 45,4 & 55,4 & 406 & 137 & 127 & 1980 & 517 & 604 & 5539 & 1209 \\
\hline 1027082104 & 79,8 & 52,5 & 63,4 & 461 & 138 & 129 & 2584 & 670 & 980 & 5537 & 1210 \\
\hline 1027082105 & 77,8 & 48,4 & 58,7 & 436 & 135 & 127 & 2627 & 616 & 691 & 5526 & 809 \\
\hline 1027082106 & 73,9 & 54,1 & 65,3 & 463 & 141 & 129 & 2565 & 672 & 1010 & 5225 & 1213 \\
\hline 1027082107 & 52,4 & 40,1 & 49,2 & 427 & 115 & 127 & 1567 & 446 & 621 & 5056 & 1205 \\
\hline 1027082108 & 57,1 & 38,1 & 46,2 & 437 & 106 & 130 & 1770 & 450 & 483 & 5243 & 1205 \\
\hline 1027082110 & 73,8 & 51,9 & 63,8 & 448 & 142 & 133 & 2603 & 574 & 580 & 5546 & 1204 \\
\hline 1027082111 & 73 & 53,2 & 63,4 & 448 & 142 & 133 & 2057 & 572 & 531 & 5526 & 1206 \\
\hline Total & 627,4 & 429,9 & 520,7 & 3935 & 1191 & 1160 & 19728 & 5052 & 6074 & 48724 & 9470 \\
\hline
\end{tabular}

Sumber EAF SMS-2 PT GRP (2021) 
Journal Of Metallurgical Engineering And Processing Technology, Vol. 2, No. 2, February 2022, pp. 47-58

P-ISSN: 2723-6854, E-ISSN: 2798-1037

\section{Perhitungan}

Perhitungan rata-rata electrical power dan arcing power di SMS-1 dan SMS-2

\section{SMS-1}

Rata-Rata Electrical Power

$=\frac{(\text { Total power consumption } \times 1000) K w h}{\text { Total tonnage }}$

$=\frac{(723 \times 1000) K w h}{1718,975 \text { ton }}$

$=420,59 \mathrm{Kwh} /$ ton

Rata-Rata Arcing Power

$=\frac{(\text { Total power consumption } \times 1000) K w h}{\text { Total power on time }}$

$=\frac{(723 \times 1000) K w h}{886 \text { menit }}$

$=816,03 \mathrm{Kw} /$ menit

2. SMS-2

Rata-Rata Electrical Power

$=\frac{(\text { Total power consumption } \times 1000) K w h}{\text { Total tonnage }}$

$=\frac{(520,7 \times 1000) K w h}{1160 \text { ton }}$

$=448,87 \mathrm{Kwh} / \mathrm{ton}$

Rata-Rata Arcing Power

$=\frac{(\text { Total power consumption } \times 1000) K w h}{\text { Total power on time }}$

$=\frac{(520,7 \times 1000) K w h}{429,9 \text { menit }}$

$=1211,21 \mathrm{Kw} /$ menit

\section{Pembahasan}

Dari data perbandingan electrical power dan arcing power pada proses EAF di SMS-1 dan SMS-2 dan setelah dilakukan perhitungan, dapat dilihat bahwa electrical powern dan arcing power dari EAF di SMS-1 lebih rendah jika dibandingkan dengan EAF SMS-2.

\section{Pengaruh Metode Charging Material terhadap Electrical Power}

Metode charging material berpengaruh pada electrical power yang digunakan di setiap proses peleburan. Pada proses peleburan di SMS-1 menggunakan sistem charging COSS shaft furnace. Pada metode ini, scrap mengalami proses preheating di dalam shaft furnace sebelum masuk ke dalam tungku. Ketika shaft sudah di bagian bawah shaft, maka scrap yang sudah di preheating tadi akan didorong oleh pusher COSS dan jatuh ke dalam tungku. Pada proses peleburan di SMS-2 menggunakan sistem charging dengan conventional charging. Pada metode ini scrap dimuat dengan menggunakan round bucket.

Hasil perhitungan rata-rata electrical power di SMS-1 dan SMS-2 yaitu, di SMS-1 sebesar 420,59 Kwh/ton dan di SMS-2 sebesar 448,87 Kwh/ton. Untuk hasil perhitungan rata-rata arcing power di SMS-1 dan SMS-2 yaitu, di SMS-1 sebesar 816,03 Kw/menit dan di SMS-2 sebesar 1211,21 Kw/menit. Dari hasil perhitungan tersebut dapat dilihat bahwa electrical power dan arcing power dari SMS-1 jauh lebih rendah dibandingkan dengan electrical power dan arcing power dari SMS-2. Hal ini dikarenakan 
pada SMS-1 scrap telah mengalami proses preheating sehingga memudahkan proses peleburan di tungku EAF. Sedangkan di SMS-2, scrap tidak mengalami proses preheating sehingga tungku EAF bekerja lebih keras dalam proses peleburan. Karena scrap tidak mengalami proses preheating, maka proses peleburan praktis hanya dilakukan oleh elektroda dengan bantuan burner. Tap elektroda yang digunakan di SMS-2 lebih besar dibandingkan dengan SMS-1, selain itu power burner di SMS2 juga lebih besar dibandingkan dengan SMS-1. Hal ini menyebabkan daya yang digunakan selama proses peleburan menjadi lebih tinggi. Oleh karena itu electrical power dan arcing power dari SMS-2 lebih besar dibandingkan dengan power consumption SMS-1.

\section{Keuntungan dan Kerugian COSS Shaft Furnace System}

Keuntungan :

1. Mengurangi konsumsi energi listrik.

2. Tidak ada heat loss.

3. Mengurangi konsumsi elektroda sekitar $10 \%$.

4. Penurunan tap to tap time sehingga menghasilkan produktivitas yang lebih tinggi.

5. Pengisian bucket dari proses peleburan dilakukan secara mandiri.

6. Pengurangan jumlah debu karena proses pemuatan dengan round bucket hanya dilakukan sekali di awal proses peleburan.

7. Jumlah scrap yang masuk terkontrol melalui sistem penimbangan yang dipasang di antara roda dan rangka COSS.
8. Input scrap terkendali terkait dengan kapasitas transformator melalui pengaturan kecepatan pendorong.

9. Mengurangi kebisingan akibat proses pemuatan scrap.

Kerugian :

1. Penggunaan sistem pemuatan dengan pusher dapat menyebabkan elektroda patah karena terdorong oleh scrap yang di dorong oleh pusher.

2. Plat bagian bawah shaft furnace cepat rusak karena tertimpa oleh scrap terus menerus sehingga diperlukan penggantians secara berkala.

\section{Keuntungan dan Kerugian Conventional Furnace System}

Keuntungan :

1. Elektroda lebih aman digunakan karena tidak terdorong oleh scrap seperti pada COSS shaft furnace charging.

Kerugian :

1. Ada panas yang terbuang (heat loss) yang disebabkan karena pembukaan roof tungku untuk proses charging materialnya.

2. Proses peleburan berlangsung lebih lama.

\section{Kesimpulan}

Dari penelitian yang telah dilakukan, dapat disimpulkan bahwa:

1. Metode charging material di SMS-1 menggunakan COSS shaft furnace sedangkan di SMS-2 menggunakan conventional furnace

2. Rata-rata electrical power pada $\begin{array}{lll}\text { SMS-1 } & \text { adalah } & 420,59\end{array}$ 
Journal Of Metallurgical Engineering And Processing Technology, Vol. 2, No. 2, February 2022, pp. 47-58

P-ISSN: 2723-6854, E-ISSN: 2798-1037

Kwh/ton,sedangkan pada SMS-2 rata-rata electrical power nya adalah 448,87 Kwh/ton

3. Rata-rata arcing power pada SMS-1 adalah 816,03 Kw/menit,sedangkan pada SMS-2 rata-rata arcing power nya adalah $1211,21 \mathrm{Kw} / \mathrm{menit}$

4. Metode COSS shaft furnace pada SMS-1 memiliki rata-rata electrical power yang lebih rendah dibandingkan dengan metode conventional furnace pada SMS-2

5. Metode COSS shaft furnace pada SMS-1 memiliki rata-rata arcing power yang lebih rendah dibandingkan dengan metode conventional furnace pada SMS-2

\section{Daftar Pustaka}

1. Cavaliere, Pasquale. 2019. Clean Ironmaking and Steelmaking Processes: Efficient Technologies for Greenhouse Emissions Abatement. Switzerland: Springer.

2. Davis, 1982. Evaluation of the Tentative JI-R Curve Testing Procedure by Round Robin Tests of HY130 Steel. Journal of Testing and Evaluation 10, no. 6 (1982): 252262.

3. Hay, Thomas dkk. 2020. A Review of Mathematical Process Models for the Electric Arc Furnace Process. Steel Research International. DOI: 10.1002/srin.202000395

4. Sporchia, Matteo. 2019. ELECTRIC ARC FURNACE AC (PART 3) The Charging Phase.

5. Sporchia, Matteo. 2019. ELECTRIC ARC FURNACE AC (PART 2) The Raw Materials.
6. Sporchia, Matteo. 2019. ELECTRIC ARC FURNACE AC (PART 1) Layout \& Components.

7. Toulouevski, Yuri N., dan Ilyaz Y. Zinurov. 2015. Electric Arc Furnace with Flat Bath Achievements and Prospects. London: Springer. DOI 10.1007/978-3-319-15886-0

8. Toulouevski, Yuri N., dan Ilyaz Y. Zinurov. 2017. Fuel Arc Furnace (FAF) for Effective Scrap Melting From EAF to FAF. Singapore: Springer. DOI 10.1007/978-981-10-5885-1

9. Wijaya, Luka. 2018. Analisis Pengaruh Variasi Arus Electric Arc Furnace Pada Proses Peleburan Direct Reduced Iron Terhadap Kandungan Fe Total dan Recovery Fe dalam Proses Pembuatan Pig Iron. Departemen Teknik Material dan Metalurgi, Fakultas Teknologi Industri, Institut Teknologi Sepuluh Nopember. 